Revista Iberoamericana. Vol. LXV, Núm. 186, Enero-Marzo 1999; 81-87

\title{
NOSTALGIA Y MELANCOLÍA EN LA NOVELA DETECTIVESCA DEL CHILE DE LOS NOVENTA
}

\author{
POR \\ Guillermo Garcia-Corales \\ Baylor University
}

La descentralización del sujeto, la fragmentación de las ideologías, el descalabro de las utopías tradicionales, la deslegitimación de la autoridad y la combinación híbrida de elementos heterogéneos, representan algunas de las configuraciones asociadas a la posmodernidad, las cuales conforman una parte significativa del sustrato ideológico y estético de las novelas chilenas publicadas en la década de los noventa por los escritores de la Generación del 80, es decir, aquellos nacidos cerca o después de 1950. En todo caso, varios autores de este período, ficcionalizan esas configuraciones de manera problemática, aludiéndolas con distancia crítica. Por una parte, establecen ciertos límites con respecto a esa fase posmoderna que se solaza con la indeterminación ética y la plurisignificación del lenguaje. Por otra, trazan estrategias narrativas que incluyen, por ejemplo, la focalización compensatoria de segmentos del pasado que resultan acogedores al contraponerse constantemente al horizonte inhóspito y desencantado del presente. Este ímpetu de carácter nostálgico y melancólico, adquiere una dinámica relevante en la narrativa detectivesca de la serie negra desarrollada en el Chile, que a partir de los noventa transita hacia la democracia después de 16 años de dictadura militar.

En esta tendencia narrativa neopolicial, que como tal se ubica en el centro de la reflexión sobre la conciencia moral de la comunidad chilena actual, resaltan las novelas ¿Quien Mató a Cristián Kustermann? (1993), Boleros en la Habana (1995) y El alemán de Atacama (1996) de Roberto Ampuero (1953-) junto con La ciudad está triste (1987), Solo en la oscuridad (1992), Nadie sabe más que los muertos (1993) y Angeles y solitarios (1995) de Ramón Díaz Eterovic (1956-). En este trabajo se discutirá Angeles y solitarios para ilustrar el perfil recién esbozado de la novela detectivesca chilena, que se destaca como "el modo privilegiado de la Generación del 80 para rescatar el pasado" (Cánovas 41). Nos referiremos, entonces, a un texto que en 1995 obtuvo el Premio de Novela del Consejo Nacional del Libro y la Lectura y en 1996 el Premio Municipal de Santiago a la mejor novela de autor chileno publicada durante 1995. Es decir, con Angeles y solitarios, Díaz Eterovic ha recibido los dos premios nacionales más importantes en el género novela. Además, en 1996, dicho texto fue finalista en el Premio Dashiell Hammet de la Asociación Internacional de Escritores Policíacos. Desde luego, estos reconocimientos constituyen una muestra adicional del buen nivel de aceptación y calidad que está logrando la novela detectivesca chilena de esta década. 
El núcleo anecdótico de Angeles y solitarios consiste en la investigación que a mediados de los noventa lleva a cabo el detective privado y protagonista, Heredia, para dilucidar los pormenores de la extraña muerte de una periodista y ex amante del policía, llamada Fernanda. Al momento de este incidente, que inicia la novela y su presente narrativo, ella se encontraba de vuelta en Chile después de trabajar cinco años en el extranjero. En un céntrico hotel de Santiago, Fernanda preparaba un reportaje sobre la fabricación de armamento en dicho país. A distinción de las aventuras de Heredia que le conocemos en las otras novelas negras de Díaz Eterovic ya indicadas, ese personaje emprende sin que nadie se lo encargue las tareas para descubrir a los criminales y castigarlos. Se ve instigado por un móvil afectivo y un porfiado afán justiciero que parece vendetta personal. Deja de lado así el oficio temporal de taxista para reiniciar sus andanzas policiales que, en un premonitorio gesto de antihéroe desencantado, el mismo califica de "un oficio tan solitario como el de las putas y los escritores" (14).

El contexto en que gira el núcleo anecdótico corresponde a un "mundo que huele mal", según el decir de Raymond Chandler (19), donde se perfila el desequilibrio de Santiago: una urbe cruzada por el narcotráfico, las componendas político-militares y las maquinaciones que incluyen la fabricación de armas químicas. Entonces, según señala el mismo Díaz Eterovic, a través de las andanzas de Heredia el texto diseña una "radiografía de nuestra sociedad actual, sobre nuestra democracia de cartón piedra que, en materia de sombras, resabios dictatoriales, negociados y claudicaciones de todo tipo, ofrece tema de sobra porque, como de costumbre, la injusticia de unos pocos se impone a los derechos y la libertad de la mayoría" ("La novela" 18).

Más allá de la anécdota policial y su contexto, el elemento que dinamiza la experiencia estética del lector corresponde a la exposición discursiva de la manera en que ese mundo que huele mal, acecha y marca al personaje, quien se debate entre la vulnerabilidad y la desesperanza, por un lado, y la necesidad vital de "no sucumbir junto al mundo que se le desploma", por otro (Mihovilovich 3). Más específicamente, el nucleo discursivo que impulsa dicha experiencia estética consiste en la propuesta de una amplia imagen de la nostalgia y la melancolía, ejecutada mediante ese lenguaje coloquial, amargo, duro, parco, humorístico y antisolemne que caracteriza al género policial negro. Junto con recrear esa imagen con significativa densidad psicológica y existencial, este modo discursivo opera en tono opuesto a cierta vertiente de la narrativa experimental posmoderna en que al lector le cuesta mucho trabajo saber hacia dónde va la trama y los personajes.

La fase psíquica más relevante de Heredia coincide con la del individuo nostálgico y melancólico según lo describe Julia Kristeva en Black Sun: Depression and Melancholia. Kristeva afirma que este individuo vive condenado al deseo y al recuerdo. Marginado de la verdadera vida, exiliado de la felicidad, padece de una condena perpetua que implica la obsesiva búsqueda de algo perdido que nunca encontrará de nuevo, con lo cual el yo que sufre la pérdida jamás puede resignarse. Por último, según Kristeva, la biografía del sujeto nostálgico se construye a través de repetidos signos de separación e inestabilidad con respecto a un presente inicuo; signos que constituyen los fragmentos de una eterna protesta (4-5).

En afinidad con este acercamiento, la imagen de la melancolía y la nostalgia en Angeles y solitarios logra credibilidad discursiva con la caracterización directa e indirecta de 
Heredia como antihéroe de fin de siglo. Esta se realiza a través de la narración en primera persona y la propia focalización del personaje con respecto a su individualidad y en relación con los espacios y circunstancias en que se mueve. Se configura un protagonista en el cual resalta un ánimo oscuro aliado con una dosis de rebeldía o "eterna protesta" que, como se dijo, caracteriza al individuo melancólico. En otras palabras, el personaje central es portador de un "pesimismo activo", al decir de Foucault (Poster 114), que lo lleva a sostener "frases mierdosas", según las califica Solis, su amigo detective, tales como: "lo único que el hombre perfecciona es su propia destrucción" (201). Heredia matiza estas acotaciones con declaraciones juguetonas como ésta: "la vida es una barca, ya lo dijo Calderón de la mierda" (268). En consonancia con este estado de ánimo oscuro y "frases mierdosas", Heredia, aunque tiene sólo 45 años de edad, aparece en escena cansado, desaliñado, con dolorosa rigidez de huesos y el hígado descompuesto por el exceso de café, licor, cigarrillos y por la mala comida en tarros. Su actividad, por lo general, toma lugar durante horas crepusculares -en un principio la novela iba a llamarse Morir de madrugada- y en ambientes decadentes propicios para que se agazape aquella imagen de la nostalgia y la melancolía advertida en el "puñado de esplín" y la "pequeña poesía de adioses", según indican los versos de Horacio Ferrer aparecidos en el epígrafe y reiterados en un par de instancias más en el texto en análisis.

El espacio privado de Heredia aporta a la credibilidad de la configuración nostálgica y melancólica. El personaje vive en un sórdido departamento-oficina en un sector venido a menos del Santiago antiguo próximo a la Estación Mapocho, desde donde todo "parece pintado con el tono gris de una tarde invernal" (83). Así, el departamento ofrece el hábitat propicio para que surja en el protagonista la obsesión de la memoria que lo perturba y redime a la vez. En efecto, desde este lugar, y quizás automatizado por su oficio policial, el detective vigila los movimientos del barrio consiatando el ir y venir de la gente por rincones que él percibe como "cargados de memoria y pequeñas miserias cotidianas" (13). Este encuentro con las miserias cotidianas incrementa la soledad del protagonista, que se traduce, según él mismo, en rabia, desencanto y "aliento del fracaso" (195).

Por otra parte, el espacio exterior también se presta para el surgimiento del estado de ánimo oscuro en el protagonista. Heredia deambula por "aquellas calles siniestras", diría Chandler (20), de un Santiago marginal y precario. Calles que forman parte de "un paisaje oscuro, vampiresco, apenas iluminado por las débiles luces de neón que indicaban la entrada a los cabarets de mala muerte; madrigueras donde las muchachas ojerosas se ganaban cuatro veintes masturbando a borrachos al amparo de cortinas impregnadas de semen urgente" (211).

En esta perspectiva pública, nuestro antihéroe de fin de siglo se irrita y entristece por los gestos posmodernos del escenario socio-político, además de lidiar con los obvios elementos criminales que, como en toda novela negra, alteran el orden rutinario y ocupan al detective. Le incomoda un país que, a pesar de su evidente desequilibrio, satura su perfil público con "cálculos económicos" y arrogantes "metáforas sobre jaguares" (21). Insinúa esto al comentar que sus amigos "se abanican con sus tarjetas de créditos, engordan en los MacDonalds y se burlan de lo que fueron antes" (212). Incluso, en observaciones que no parecen contaminadas con su estado de ánimo oscuro, se observa su desdén con respecto a esa modernidad exacerbada que lo rodea. Por ejemplo, al presentarnos a su amigo Anselmo, 
un picaresco vendedor de diarios instalado en un quiosco aledaño al departamento de Heredia, éste lo describe portando los emblemas manoseados de un supuesto capitalismo avanzado:

\begin{abstract}
Vestía jeans gastados, una polera que recordaba el recital de Rod Steward en el Estadio Nacional y un gorro con la insignia de los Toros de Chicago. En su mano izquierda traía una hoja, y en la derecha un celular que me recordó su reciente obsesión por la chucherías electrónicas. Seis meses atrás había vendido la casa heredada de una tía lejana para invertir el producto de la venta para proveer su quiosco de fax, televisor conectado al tevé cable, un microhorno que utilizaba para recalentar completos y un computador personal cargado de varias docenas de juegos[...] $(150-1)$.
\end{abstract}

Esta burla planteada de soslayo acerca del seudo progreso, también se presenta con giros sarcásticos más subidos de tono dirigidos a otros personajes, pero que en un juego metonímico recaen sobre la escena socio-política. Así sucede, por ejemplo, cuando se refiere a Jerónimo Larios, un periodista que le servirá en sus investigaciones. Heredia afirma: "Lo recordaba de terno oscuro y al momento del reencuentro vestía traje de lino color guinda, camisa listada y una corbata ancha, italiana. Quería ser un petrimetre postmoderno y su porte sólo le permitía parecer la réplica minúscula del Tony Caluga" (139-40). Se desprende, entonces, que la tontificación de los chilenos a través de la publicidad y el consumismo motivan en el detective una "eterna protesta", mediatizada a veces por un humor negro dirigido a esa realidad que para él "es más perversa de lo que la gente imagina" (88). Tal actitud coincide un tanto con la visión de los chilenos que fueron contrarios a la dictadura de Augusto Pinochet y lucharon por recuperar la democracia, y que cuando ésta, en apariencias, volvió, se dieron cuenta que era una democracia controlada por el poder de quienes sustentaron esa dictadura y de quienes detentan el control económico.

Detrás de la mueca de burla y desencanto hecha a la sociedad en que se impone el olvido como clave para un entendimiento nacional y se endiosa el individualismo y los bienes materiales, emerge en primera instancia la nostalgia de un país que hasta principios de los 70 era más humilde, pero más auténtico y solidario. De este modo, se evidencia ese impulso de cierta heroicidad del investigador a "no sucumbir" cuando se le han derrumbado casi todas las ilusiones y las utopías. Además de sus afanes policiales por conseguir aunque sea una dosis mínima de verdad y justicia en un mundo que gira en sentido contrario a esos principios, Heredia se aferra, entonces, a la nostalgia que en el texto equivale a la memoria considerada como "el único gesto válido y consecuente" (96). Es decir, este Quijote degradado, sin fe ni fortuna, amante de las frases de "otros tiempos" (276), es nostálgico de una época en que se podía soñar con otro futuro; la cual se formula con la expresión "la felicidad de los veinte años" (150). Expresión que se transforma como en un leit motif de la sensibilidad nostálgica en el texto. En torno a esto, Díaz Eterovic afïrma: "se trata en definitiva de la nostalgia de mi generación. De quienes éramos jóvenes el año 1973 y tuvimos que vivir años importantes de nuestras vidas rodeados por la oscuridad, por el miedo, y que nunca, tampoco ahora, hemos tenido la oportunidad de construir nuestros proyectos, salvo, algunos, en el plano de la creación artística, de la literatura en mi caso" (entrevista inédita). Este enlace de la tensión nostálgica y melancólica con el acontecer socio-político es considerado por Kristeva cuando observa que los períodos de crisis que 
presencian la caída de los ídolos políticos y religiosos son particularmente favorables a los estados de ánimo oscuros. Es decir, la melancolía se reafirma en los tiempos de crisis, se verbaliza, establece su arqueología, genera sus representaciones y su conocimiento (8).

Ahora bien, si lo indicado hasta aquí tiende hacia una lectura política de la nostalgia y la melancolía de nuestro antihéroe que se debate en la crisis de fin de siglo, se puede plantear también que el texto en su conjunto trasciende esa dimensión. Muestra así la ductilidad de un discurso narrativo inscrito dentro de un género literario "tan vituperado tradicionalmente" como es la narrativa negra (Vázquez 53). En efecto, la imagen de la melancolía que cruza el relato de Díaz Eterovic coincide con la definición de este sentimiento que ofrece Murena en La metáfora y lo sagrado. La melancolía, según Murera, es la nostalgia de la criatura por algo perdido o nunca alcanzado; nostalgia de un mundo que falta de modo irremediable. En cuanto al engarce de ese dolor sentimental con el arte y por ende con la literatura, Murena plantea que aunque tal nostalgia se expresa en relación a objetivos mundanos, éstos no son nunca más que ocasiones tomadas para expresar la nostalgia fundamental respecto a lo imposible, porque la esencia del arte es nostalgia por el "Otro mundo", por lo cual se enlaza con las corrientes más profundas e inalienables de la genuina experiencia literaria (25-26).

En la trizada existencia de Heredia emergen huellas de esa nostalgia fundamental a que se refiere Murena, aunque el personaje se mantiene dentro de ciertos rasgos convencionales del antihéroe del género policial negro: un individuo lacónico, acosado por el entorno, ajeno a las elucubraciones filosóficas y portador de una "esperanza decepcionada", como diría Ernst Bloch (5). Aquellas huellas no sólo están íntimamente entroncadas a objetos, personas y momentos de su propia experiencia vital - tales como la música de Los Beatles o Los Ramblers, la literatura de Onetti, Cortázar y Hemingway, o las mujeres que le han interesado - sino que lo remiten también a aquello encapsulado en esa supuesta "felicidad de los veinte años" a que hace referencia el narrador. Y a su vez, con todo esto se evoca una nostalgia más profunda asomada en la presencia constante de una imagen fantasmática. Parafraseando a Murena, se trataría de una imagen irremediablemente distante y eternamente otra, sin temporalidad fija, situada más allá de todo lo visible, más allá de todo lo posible. En este sentido, las constantes citas literarias de Heredia lo conectan con los libros y autores que ama y prefigura como objetos de nostalgia, pero esos libros y autores lo remiten también a otros objetos más indeterminados de la sensibilidad nostálgica y melancólica. Emerge así el proceso parecido a ese constante desplazamiento de significantes y significados implicado en la misma experiencia literaria. De este modo, el protagonista no sucumbe ante los avatares de su propia historia en el mundo que se desploma y, a su vez, sobrevive como atractivo y perdurable personaje literario frente a lo ojos del lector.

Irónicamente, una muestra de aquella imagen fantasmática se representa mediante la persona que Heredia tiene más cerca durante la investigación criminal: una hermosa muchacha llamada Griseta. Ella es hermana de un revolucionario, Juan, quien después de combatir la dictadura en Chile, se unió a los sandinistas y murió en un ataque de los Contras. Aunque la intromisión de la muchacha parece ser tan sorpresiva y atrayente en sí mismacomo la entrada de un ángel en la casa de un solitario, según lo sugiere el título de la novelaella de inmediato impulsa los recuerdos de Heredia hacia su amigo Juan y las correspondientes ilusiones y luchas que compartieron durante los tiempos de la mencionada "felicidad de los 
veinte años". Y luego, cuando Heredia acepta la compañía amorosa de Griseta, casi de inmediato comienza a configurar la presencia de la joven como un ser fantasmático, mediatizado por la sensibilidad nostálgica de aquél. La describe con un lenguaje que recuerda a la mujer amada del Neruda romántico de Veinte poemas de amor y una canción desesperada. En efecto, ese maltratado, duro y perplejo detective percibe a Griseta como una joven "suave y casi transparente" (145) y lo remite a otra figura femenina, la desaparecida Fernanda, a quien a su vez el detective visualiza con los atributos fantasmáticos de lo bello, misterioso y fugaz (13). La obsesión con lo efímero de las cosas, es decir, la aguda y dolorida conciencia nostálgica de un mundo que falta de modo irremediable, se ilustra cuando Heredia recuerda una carta de Fernanda en que ésta le decía "ahora lo nuestro es un amor de recuerdos y ausencias" (129). Frase que, por su disposición textual, el lector asocia de inmediato al sentimiento del detective acerca de su vínculo con Griseta cuando éste recién comienza. El mismo gato Simenon - expresión estética y surrealista de la conciencia del detective - confirma la inclinación de éste a dolerse por alimentar la sensación de que hay algo muy querido que siempre se le escapa de las manos. Simenon lo confronta afirmando: "Una mañana despertarás pensando que ella [Griseta] es importante; y luego, cuando ya no la puedas retener, te costará engañar a tu soledad" (186).

Finalmente, digamos que ese deseo de lo imposible que se despliega en la fícción se inscribe en la imaginación utópica y su constante problematización en los tiempos actuales. De esta vertiente emergen ciertas proyecciones alegóricas de los textos literarios contemporáneos que, como sucede con Angeles y solitarios, en un primer nivel discursivo perfilan biografías de personajes melancólicos y nostálgicos. Si, según Walter Benjamín, lo que mejor alcanza la tensión melancólica es la alegoría (Kristeva 101), resulta factible acotar que en nuestra época de gestos posmodernos esa proyección alegórica evoca el naufragio de las utopías tradicionales o, parafraseando a Kristeva, la caída de los ídolos políticos y religiosos. Naufragio o caída que insinúa el detective Solís cuando (actuando como una figura especular de Heredia) observa: "Nosotros Heredia. La ilusión; el entusiasmo para machacarnos el alma por nada. Los putos principios, las ganas" (204). En la novela detectivesca del Chile de la década del noventa, ese impulso alegórico alude, en versión criolla, al resquebrajamiento de las grandes narrativas de la historia occidental tales como los esquemas de la emancipación colectiva y de la unidad del espíritu junto con la relativización de los saberes consagrados, según diría Jean-François Lyotard (xxiii). En suma, este discurso nostálgico y melancólico recicla la conciencia desgarrada y fragmentada del sujeto actual que, aferrado sólo a fragmentos de utopías trizadas, navega cada vez más lejos de esa mejor vida, proyectada alegóricamente en otras tierras, en otros mares y en otros tiempos. Discurso que en el caso de Angeles y solitarios de Díaz Eterovic, y como lo indica Patricia Espinosa, consiste en una escritura rigurosa y metódica, fundada en el dúctil y variado manejo de los recursos lingüísticos y temáticos, que hace imposible no creer en el melancólico pesimismo de Heredia y sus circunstancias, entroncado plenamente con la gran tradición narrativa nacional en torno de la tristeza (4). 


\section{Obras Citadas}

Bloch, Ernst. The Principle of Hope. Oxford: Basil Blackwell Ltd., 1986.

Cánovas, Rodrigo. La novela chilena. Nuevas generaciones. Santiago: Ediciones Universidad Católica de Chile, 1997.

Chandler, Raymond. The Simple Art of Murder. Canada: Houghton Miffin Company, 1984.

Díaz Eterovic, Ramón. Angeles y solitarios. Chile: Planeta Biblioteca del Sur, 1995.

"La novela policial en Chile. Angeles y solitarios". Punto Final (Santiago, diciembre de 1995): 18.

Espinosa, Patricia. "Santiago de noche". La Época. "Suplemento de Literatura y Libros" (11 de febrero de 1996): 4.

García-Corales, Guillermo. "La generación emergente de escritores chilenos: el caso de Ramón Díaz Eterovic" (entrevista inédita).

Kristeva, Julia. Black Sun: Depression and Melancholia. Leon S. Roudiez, trad. New York: Columbia University Press, 1989.

Lyotard, Jean-François. The Postmodern Condition. Minneapolis: University of Minnesota Press, 1984.

Mihovilovich, Juan. "Ángeles y solitarios: la consolidación de Heredia". La Época. "Suplemento de literatura y libros" (14 de enero de 1996): 3.

Murena, Héctor A. La metáfora y lo sagrado. Barcelona: Editorial Alfa, 1984.

Poster, Mark. Political Theory and Poststructuralism. In Search of a Context. Ithaca/ London: Cornell University Press, 1989.

Vázquez de Parga, Salvador. "Panorama internacional de la novela negra". Quimera 7980 (1988): 50-53. 
